\title{
Las Memorias del duque de Sully (o los avatares del primer proyecto de unión europea)
}

\author{
The Memories of the Duke of Sully (or the ups and downs \\ of the first project of European union)
}

GERMAN A. DE LA REZA*

Rev. Bras. Polít. Int. 52 (2): 102-114 [2009]

\section{Introducción}

Cuando Maximilien de Béthune, duque de Sully, publica en 1638 los primeros tomos de Mémoires des sages et royales aconomies d'Estat, domestiques, politiques et militaires de Henri le Grand ${ }^{1}$ no podía suponer que su obra iba a estar envuelta en prolongadas polémicas. Sus apretadas páginas, la mezcolanza de historia nacional, crónica palaciega, documentos oficiales y un estilo farragoso, hacían de las Memorias un trabajo en nada superior a otras publicaciones de los funcionarios destacados de Francia. Sin embargo, una de sus partes, el proyecto de confederación europea, se abre camino a través del tiempo, pasando de controversias a periódicas rehabilitaciones hasta afirmarse como el primer antecedente intelectual de la Unión Europea.

El presente artículo se consagra al análisis de las Memorias del duque de Sully, a las versiones, controversias y significados que subyacen a su redacción, edición y difusión. Con ese propósito, el trabajo ha sido estructurado en siete secciones. La primera refiere brevemente el contexto que rodea la preparación de la obra; la segunda presenta las características generales de la confederación y la tercera profundiza en las discrepancias de sus versiones. En la cuarta, quinta y la sexta se estudian la cronología y las etapas de la redacción, los cambios operados en los manuscritos (sobre todo los que atañen a la misión apócrifa de 1601) y sus

\footnotetext{
* Profesor-investigador de la Universidad Autónoma Metropolitana, Unidad Azcapotzalco. Investigador externo en el Centro de Estudios Europeos, Universidad Nacional Autónoma de México(delareza@servidor. unam.mx).

1 Maximilien de Béthune, duque de Sully, Mémoires des sages et royales aconomies d'Estat, domestiques, politiques et militaires de Henri le Grand, l'exemple des rois, le prince des vertus, des armes et des lois et le père en effet de ses peuples français; Et les Sertitudes utiles, obéissances convenables et administrations loyales de Maximilien de Béthune, l'un des plus confidents, familiers et utiles soldats et serviteurs du Grand Mars des Français, Tomos I-II, París: Michaud y Poujoulat, Vol. I-II, 1837.
} 
vías de difusión. La séptima examina el debate sobre la anterioridad histórica de las Memorias sobre la obra de Émeric Crucé y ofrece sus propios argumentos con base en la historiografía de la época.

El artículo adopta el enfoque de la historia de las ideas: pretende reconstruir las condiciones que determinan la elaboración y recepción del primer proyecto paneuropeo.

\section{Superintendente de finanzas}

El duque de Sully, célebre superintendente de finanzas del rey Enrique IV de Francia, nace en una familia de hugonotes franceses el 13 de diciembre de 1559 en Rosny-sur-Seine y fallece en Villebon el 22 de diciembre de 1641 a la edad de 81 años. Su nombre está asociado a los logros de Enrique IV, de quien es cercano colaborador entre marzo de 1572 y mayo de 1610, fecha cuando este último es asesinado por un fanático religioso. Se le atribuye una conducción acertada de los asuntos económicos, habiendo ordenado la hacienda y relanzado las actividades productivas devastadas a consecuencias de largas guerras intestinas. Junto con el soberano, promueve la independencia de los magistrados; impulsa la actividad agrícola; impide las uniones entre grandes familias, haciendo posible la unificación francesa; controla la acción de los acreedores extranjeros; desmantela los puntos de peaje que impedían el libre flujo de mercancías dentro del país; organiza la reforestación y el cuidado de las aguas y faunas de Francia; amplía el Louvre y en su recinto da alojamiento a artistas y artesanos. ${ }^{2}$

Además de la superintendencia, Sully ocupa los cargos de Consejero de Estado, Gobernador de la Bastilla, Gran Maestre de puentes y caminos, y pudo haber detentado la máxima responsabilidad militar de haber aceptado convertirse al catolicismo, la religión de la monarquía gala. ${ }^{3}$ Durante su gestión adquiere el título de duque y debido a sus múltiples ingresos e inversiones, amasa una de las grandes fortunas del país. ${ }^{4}$

2 Cf. Jules Michelet, Histoire de France au dix-septième siècle. Henri IV et Richelieu, tercera edición, París: Chamerot, 1861, págs. 137-147. La leyenda de buen administrador de Sully está estrechamente ligada a su promoción de la agricultura, labor reconocida en especial por François Quesnay. Cf. David Buisseret, "The Legend of Sully", The Historical Journal, Vol. 5, No. 2, 1962, págs. 181-188. A Enrique IV se le atribuye también haber reconocido la no disolución del parlamento, siendo mencionado como argumento de autoridad durante el periodo prerrevolucionario. Cf. Anónimo, Sentiment de Henri IV sur la question de l'indissolubilité du parlement, avec des réflexions historiques sur cette matière importante, s.i 1788.

3 Para ocupar el cargo, Enrique IV le exige a Sully que se convierta al catolicismo como él mismo lo había hecho tiempo atrás siguiendo sus recomendaciones. Todo indica que Sully pretendió el puesto sin cambiar de religión, lo que generó tensiones dentro del gobierno. Sobre este aspecto de su vida, incluyendo las estrategias para lograr el favor del rey y promover su persona, véase Edmund H. Dickerman, "Conviction, Ambition and the Genesis of Sully's Économies Royales”, The Historical Journal, Vol. 30, No. 3, septiembre, 1987, págs. 513-521.

4 La evolución de la fortuna del ministro comprende tres grandes periodos: (1) Primeras casi cuatro décadas, durante las cuales Sully acompaña al futuro rey Enrique IV en su sinuoso y prolongado camino al poder -su 
Luego de la muerte de Enrique IV, Sully se retira a su castillo en Rosny y en una atmósfera no exenta de sobresaltos redacta sus Memorias. Para ello apela a un diario fragmentario y a diversos documentos oficiales, incluyendo las memorias de los asuntos tratados en el Consejo de ministros y las minutas de las conversaciones con el rey. Es posible que Sully formara su voluminoso archivo personal con un fin estrictamente memorialístico y luego cambia de propósito ante la hostilidad que percibe en la Regente María de Médicis y cuando aparecen varias obras que critican al fallecido soberano o dejan en la sombra su obra, en particular las Lettres del cardenal d'Ossat, las Memoires d'Éstat de Villeroy y la Histoire de France de Scipion Dupleix. Con la ayuda de dos, luego cuatro secretarios, y después de múltiples retoques y adiciones, Sully convierte el manuscrito en un amplio y documentado informe sobre aquellos actos de gobierno en los cuales tuvo un papel importante por ser su inspirador o el instrumento de su ejecución. ${ }^{5}$

\section{Confederación europea}

En Lettre de M. de Sully au Roy, uno de los documentos de las Memorias, propone la creación de "un cuerpo común de República cristiana siempre pacífica en ella misma que esté compuesta de todos los estados, reinos, repúblicas y señoríos que hagan profesión de fe cristiana en Europa". ${ }^{6}$ A pesar de su carácter ecuménico, el proyecto excluye a dos países: Turquía, por albergar a los "enemigos de la Ley" y ocupar Tierra Santa, y Rusia por encontrarse mayoritariamente en Asia, incorporar a naciones paganas y profesar un rito cristiano distinto al europeo. ${ }^{7}$ El mecanismo destinado a sellar la paz entre los estados asociados es el arbitraje internacional, administrado por un congreso de comisarios renovable cada tres años y cuyas funciones generales abarcan el análisis y la propuesta de soluciones para los asuntos corrientes de la confederación. ${ }^{8}$

Dos condiciones importantes presiden la creación de la República cristiana: la reorganización territorial de algunos países con el fin de equilibrar las relaciones

situación económica es relativamente precaria. (2) Doce años de actividad pública como principal ministro del rey, los cuales son altamente benéficos para sus ingresos. (3) Una treintena de años de retiro, periodo en el cual agranda y defiende su patrimonio. Antes de 1598, los ingresos de Sully sumaban 328 mil libras (no se tiene suficiente evidencia más que de la mitad de esa suma); entre 1598 y 1610, en cambio, aumentan a 2 millones 311 mil libras y al final de su vida su fortuna bordea los cinco millones de libras. Es uno de los hombres más ricos del país, aunque está lejos del célebre Cardenal Richelieu, quien posee al momento de su sucesión en 1642 una riqueza valorada en 22 millones 400 mil libras. Cf. Isabelle Aristide, La fortune de Sully, París: Ministère de l'Économie, des Finances et du Budget, s.f.

5 Henri Carré, Sully : Sa vie et son æeuvre 1559-1641, París: Biliothèque Historique, 1932, reedición a cargo de Payot, 1980, págs. 375-376.

6 Duque de Sully, Economies royales, Ob. cit. Vol. II, París, 1837, pág. 213. Para un análisis de la obra de Sully véase: André Puharré, L'Europe vue par Henri IV et Sully d'après le "Grand Dessein" des Économies royales. Avec de larges extraits des Mémoires de Sully, Pau: Monhélios, 2002.

7 Duque de Sully, Economies royales, Ob. cit. Vol. II, pág. 348.

8 Ob. cit. Vol. II, pág. 217. 
intraeuropeas y la defensa del principio de tolerancia religiosa, cara al pensamiento y las acciones de Enrique IV y de su principal ministro. La primera conduce a Sully a redefinir el mapa político europeo sobre la base de criterios de nacionalidad (entendida lingüísticamente) y relativa paridad en el poderío militar, económico y territorial. Su propósito no se basa en un principio general, sino que busca limitar la influencia de la Casa de Austria mediante la reducción de sus posesiones fuera de España. ${ }^{9}$

La tolerancia religiosa la hace depender del argumento según el cual es imposible fusionar los credos cristianos europeos:

"aquel que quisiera resolver las creencias religiosas y reducirlas a una sola, advierte, se arrojaría a un laberinto sin salida y se expondría a penas y trabajos innumerables, de igual manera que si quisiera sondear los decretos de la Divinidad, penetrar en sus intenciones e investigar las causas por las cuales Dios (Él que tiene las voluntades y las acciones de los hombres en su mano) deja a una gran cantidad de pueblos errar a la aventura." 10

Rechaza las motivaciones religiosas como justificación de la guerra; en su lugar, los monarcas deberían dejar que Dios se ocupe del "régimen de los espíritus [...] y contentarse con los servicios corporales para los asuntos civiles y temporales". ${ }^{11}$ La regla práctica de la tolerancia es que "nadie [puede ser] perseguido en su persona ni en sus bienes" a causa de sus opiniones religiosas. A cada monarca le corresponde por derecho fijar el orden religioso que desea establecer en su reino, pero aquellos ciudadanos que no profesen alguno de los cultos reconocidos en el país, se les debe permitir abandonarlo con todos sus bienes en el plazo de un "año y un día". ${ }^{2}$

\section{Características organizativas}

Las características de la confederación se precisan en dos proyectos sucesivos. El primero prevé un congreso compuesto de 66 diputados, nombrados por tres años de acuerdo con la siguiente distribución: cuatro representantes por cada potencia mayor (Papado, Francia, España, Gran Bretaña, Dinamarca, Suecia, Polonia y el Señorío de Venecia); y dos por cada potencia media (Hungría,

9 Ob. cit. Vol. II, págs. 214 y 217. Ese objetivo está estrechamente ligado a la política exterior de Enrique IV, quien puso particular empeño en limitar el poderío de Felipe II (objetivo parcialmente logrado con el Tratado de Vervins) y en restarle capacidad de restablecimiento a la Dinastía de los Habsburgo. Para llevar a cabo esa estrategia se apoya en sus embajadores en Inglaterra y Alemania. Jacques Bongars, en particular, arma a los príncipes alemanes y promueve su unión. El análisis y la documentación referente a las misiones de Bongars se encuentran en: Léonce Anquez, Henri IV et l'Allemagne d'après les Memoires et la correspondance de Jacques Bongars, París: Hachette, 1887. El periodo estudiado por Anquez va de la campaña de 1590 al año 1610.

10 Duque de Sully, Economies royales, Ob. cit. Vol. II, pág. 116.

11 Ob. cit. Vol. II, pág. 216.

12 Ob. cit. Vol. II, pág. 430. 
Bohemia, Nápoles, Sicilia y Cerdeña, los cantones de Suiza, los Países Bajos, los ducados de Florencia, Milán, Saboya, Mantua, Parma, Modena y Génova). ${ }^{13}$ Las sedes del cuerpo deliberativo las elige atendiendo a la equidistancia de los países representados: Cracovia para los delegados de Polonia, Suecia, Dinamarca y Alemania; Trento para Suiza, Tirol, Hungría, Nápoles, Sicilia y Candia; y París o Burgos para Francia, España, Gran Bretaña y Países Bajos.

El segundo proyecto, redactado varios años después que el primero, instituye un consejo general encargado de atender las reclamaciones de todos los países miembros y seis asambleas "particulares" o regionales. ${ }^{14} \mathrm{El}$ consejo general se compone esta vez de 40 representantes, la mitad de ellos provenientes de las grandes potencias y la otra mitad de los estados pequeños, permitiendo así que las resoluciones importantes de la confederación resulten del acuerdo de ambos grupos de países. A esa dinámica de equilibrios le agrega la participación diferenciada en el esfuerzo defensivo; los "grandes" deben contribuir con 58\% de los efectivos, $62 \%$ de los caballos y $55 \%$ de las piezas de artillería de las fuerzas confederadas. La fuerza naval, rubro en el cual algunos estados pequeños disponen de importantes recursos, las potencias mayores participan con sólo $42 \%$.

El consejo continental tiene por función recabar las propuestas generales y regionales, siendo competente en "todos los objetivos, las guerras y los asuntos que importen a la República cristiana". Esas facultades instituyen un derecho de injerencia en los asuntos internos de la confederación, además de autorizar su participación en el diseño de la política exterior. Otra función importante del consejo la pone en el estado de representar la última instancia de revisión de las decisiones de los consejos particulares. En conclusión del segundo proyecto, Sully recomienda que el consejo general sesione rotativamente en Metz, Luxemburgo, Nancy, Colonia, Frankfurt, Basilea, Heidelberg, mientras que los consejos particulares encargados de resolver los problemas específicos de cada localidad, debían hacerlo en Dantzig, Nüremberg, Viena, Bolonia y Constanza, dejando la sede de la sexta asamblea a elección de sus miembros.

\section{Etapas en la elaboración de las Memorias}

La mayor parte de las controversias que rodean a las Memorias tienen que ver con el proyecto anfictiónico y sus distintas versiones. De acuerdo con las primeras investigaciones en el archivo de Sully, a cargo de Christian Pfister, la redacción de la obra comprende tres manuscritos. El primero empieza a redactarse hacia 1611 y está listo alrededor de 1617; el siguiente comprende el periodo 1618-1638 y concluye con la edición de los primeros dos tomos; el último se prolonga hasta

13 Ob. cit. Vol. II, pág. 117.

14 Ob. cit. Vol. II, págs. 151-152. 
1662, cuando se imprime póstumamente la última parte de la obra. ${ }^{15}$ El posterior descubrimiento de un manuscrito en posesión del Marqués de Rosanbo, ha permitido establecer una cronología y un número de etapas más exactos. Según David Buisseret y Bernard Barbiche, la obra se compone de seis versiones:

(1) Primera redacción, consistente en un borrador de 69 páginas, revisado y corregido por Sully (manuscrito de Rosanbo).

(2) Segunda redacción, más desarrollada y anterior a 1617, incorporando 145 cartas dirigidas a Sully por el rey y por Villeroy entre 1594 y 1604 , sin estructura capitular y con señalamientos de donde deberían ir las correspondientes separaciones.

(3) Tercera redacción, conservada parcialmente, donde se incluyen las observaciones de Sully respecto de la capitulación y los errores de copiado; no difiere sensiblemente de la segunda redacción y a su vez contiene numerosas anotaciones hechas a mano por Sully.

(4) Cuarta redacción, compuesta de un manuscrito que abarca el periodo 1594-1595 y que también contiene varias correcciones de Sully.

(5) La "edición de 1638", compuesta de dos tomos in-folio; a pesar de la fecha que figura en el frontispicio, la efectiva publicación interviene después: los trabajos de edición empiezan en los primeros meses de 1639 y duran por le menos un año más. Existen falsas ediciones que se diferencian del original por algunos detalles.

(6) "Edición de 1662" a cargo de Augustin Courbé, la cual reúne en un volumen de los tomos tercero y cuarto; el primero cubre el periodo 1606-1610 y el siguiente los sucesos acaecidos después del fallecimiento de Enrique IV.

\section{Documentos apócrifos}

La utilidad de estas investigaciones pronto se hace evidente. Al comparar el manuscrito de 1617 y la edición de 1638, Pfister confirma la sospecha de que las Memorias incorporan documentos apócrifos relacionados con el apoyo de Enrique IV a la creación de la República cristiana. ${ }^{16}$ Estos documentos, en general cartas o minutas sin fecha, relatan una supuesta embajada de Sully en Inglaterra en 1601,

15 David Buisseret y Bernard Barbiche, "Introduction", Les aconomies royales de Sully, Tomo I 1592-1594, París: Klincksieck, 1970, págs. xvii-xxiii. Todas las fuentes asumen que la primera edición se publica en dos volúmenes; el primer tomo abarca el periodo 1572-1600 y el segundo los años 1601-1605.

16 Christian Pfister, "Les 'CEconomies royales' de Sully et le Grand Dessein de Henri IV", Revue historique, Tomo 54, 1894, págs. 300, 306 y 313-314. El artículo aparece en la Revue historique en tres tomos: 54, págs. 300-324; 55, págs. 67-82; y 56, págs. 39-48. Pfister pasa en revista las aserciones de las Memorias, sus transformaciones y cronologías. En la Histoire de France au dix-septième siècle. Henri IV et Richelieu, Ob. cit. págs. 471-472, publicada en mayo de 1857, Michelet hace una clara diferencia entre el sistema de alianzas de Enrique IV y el "plan completamente utópico de Sully". Según Michelet, las Memorias son ideadas por los secretarios del superintendente en 1627, durante el asedio de la Rochelle. 
cuando habría concertado con la reina Elizabeth la creación de los acuerdos de base para la confederación europea. En torno a esa misión, Sully monta otros hechos y anécdotas destinados a dar un semblante de factibilidad a un proyecto por muchos considerado utópico. Una de las cartas se interroga sobre las ventajas de "seguir todo lo que había sido convenido entre el rey de Francia y la reina de Inglaterra en 1601"; otra señala que ese año (1601) fue el punto de partida de los tratados internacionales que pretendían echar las bases de una futura confederación. ${ }^{17}$ Sully hace depender su viaje de una carta recibida de la reina de Inglaterra, la cual Adrien Desclozeaux demuestra que también es falsa. ${ }^{18}$

Antes de avanzar en nuestro argumento, consideremos una evidencia adicional sobre el carácter apócrifo del Gran Designio: el elogio póstumo de una veintena de páginas versificadas en edición bilingüe (francesa y latina) que Sully redacta en honor de Enrique IV cinco años después del fallecimiento de éste. ${ }^{19}$ Para realzar la vida y las obras del soberano, Sully las compara con los hechos dignos de memoria del emperador Cesar. Siguiendo ese criterio, versa sobre la similitud de orígenes, de actos de gobierno, de batallas ganadas y perdidas, de obras públicas, etcétera. La prolijidad del paralelo lo lleva a incluir hechos poco relevantes, como los rasgos comunes de sus enemigos o el haber reducido la duración de las misas, pero nunca menciona al Gran Designio o a la República cristiana.

¿Cuáles son los motivos que mueven a Sully a realizar alteraciones de tanta importancia en su manuscrito? Sin duda, algo cambia en la vida del antiguo superintendente durante los arreglos de la edición de 1638. Edmund Dickerman ha explorado esa vertiente y observado que a la caída de la Regente, el rey Luís XIII, hijo del Enrique IV, convoca en 1617 a los antiguos ministros de su padre para que integren su gabinete con una excepción, el antiguo superintendente. Sully, que albergaba esperanzas de regresar a gobierno y había compuesto su libro como un "último intento desesperado por volver al poder", ve canceladas sus posibilidades y, según Dickerman, hace algunos cambios pensando en la posteridad de su obra. ${ }^{20}$ Aunque plausible, esta explicación no aclara un aspecto central de su hipótesis: ¿por qué el ministro favorito de Enrique IV habría preferido como

17 Duque de Sully, Economies royales, Ob. cit. Vol. I, pág. 429; Vol. II, pág. 216.

18 Adrien Desclozeaux, "L’Ambassade de Sully en Angleterre en 1601 et les 'Économies royales", Revue historique, Vol. 54, 1890, págs. 68-71. Véase también Pierre Paul Laffleur de Kermaingant, L’Ambassade de France en Angleterre, Tomo II "Mission de Jean de Thuméry, sieur de Boissise, 1597-1602", París: Georges Chamerot, págs. 553-557.

19 Duque de Sully, Paralèlles de César et de Henry le grand par Monsieur le Duc de Sully, París: Toussainct du Bray, 1615, págs. 3-22. El poema aparece con algunos cambios en la edición de 1638 de las Memorias. Sully se refiere al papel unificador de ambos soberanos sobre todo en la página 10; en el caso de Enrique IV se trata de la unificación francesa. Esta obra retoma el tipo de elogio empleado anteriormente por Antoine Bandole en Les Parallèles de César et de Henri IIII par Anthoine de Bandole, avec les Commentaires de César et les annotations de Blaise de Viginère, de nouveau illustrez de maximes politiques par ledit de Bandole, París: J. Richer, 1609.

20 Edmund H. Dickerman, "The Man and the Myth in Sully's Economies Royales", French Historical Studies, Vol. 7, No. 3, verano, 1972, pág. 317 y ss. El autor revisa la objetividad de los textos de Sully y concluye que en varias ocasiones el ministro exagera o incluso distorsiona los hechos. 
tema de sus argucias al Gran Designio y no otro menos polémico y de prestigio seguro? Como se dijo, en vida de Sully el proyecto anfictiónico se considera utópico y quienes descreen de la participación del rey lo hacen en parte para salvaguardar la memoria del soberano.

Una lectura matizada de la obra de Sully sugiere razones más complejas. El intento de Enrique IV de crear una vasta alianza europea, llevado a cabo personalmente por el superintendente a partir de 1603, es complementario y en algunos puntos coincide o puede considerarse como una primera etapa en la creación de la confederación continental. Cuando Sully acude a la corte británica en junio de ese último año, lleva consigo un pliego de instrucciones oficiales preparadas por el Consejo de gobierno, pero también un mensaje secreto de cuya exposición verbal es el único encargado. Aunque se conoce el contenido del documento, orientado precisamente a la creación de dicha alianza, no es posible saber los alcances que le dio Sully. ${ }^{21}$

En la evaluación del caso oportuno tener en cuenta la rectitud y honestidad de Sully, las cuales tuvieron transposición en la primera gestión transparente de la historia de Francia: Desde 1600, cuando asume en cargo de Gran Maestre y capitán de Artillería, hasta su salida de gobierno en 1610, establece como regla general administrativa el que todas las actas de compra y venta de su gobierno se registren ante notario público. Las 278 actas disponibles hoy en día, se refieren a bienes públicos, $\mathrm{y}$ algo excepcional para la época, también a bienes privados. ${ }^{22}$ Otro factor que reclama en este caso indulgencia hacia el antiguo superintendente, es que en 1638 Sully cuenta con 78 años de edad y que las últimas revisiones de las Memorias las realiza en estado enfermo tres años antes de su muerte.

\section{Difusión de la obra}

Como se dijo, Sully se apoyó en cuatro secretarios para la última fase de las Memorias. Su función fue principalmente literaria, aunque es probable que representaran también una suerte de parapeto ante eventuales exacciones gubernamentales. ${ }^{23}$ El primer indicio de ese propósito lo da el estilo de la obra: Sully

\footnotetext{
21 Sobre la embajada extraordinaria de Sully en 1603 y el tenor de las instrucciones secretas, véase: Pfister, "Les 'EEconomies royales' de Sully et le Grand Dessein de Henri IV”, Ob. cit. Tomo 55, págs. 66-71. Para un relato sobre las circunstancias del viaje a Inglaterra, véase: Carré, Sully, Ob. cit. págs.127-140.

22 Las actas económicas y las minutas del proceso notarial representan una de las mejores fuentes para la historia económica de la época, sin paralelo con la información disponible para gobiernos anteriores o incluso posteriores. Cf. Duque de Sully, Les actes de Sully passés au nom du roi de 1600 à 1610 par-devant M. Simon Fournyer, notaire au Châtelet de Paris, dont les minutes son conservées en l'étude de M. Henri Motel, notaire à Paris, recueillis, publiés et annotés par M. F. de Mallevoue, París: Imprimerie Nationale, 1911.

23 De la primera a la cuarta versión, la forma de presentación del manuscrito es de un secretario que le recuerda a Sully los hechos sobresalientes de su gobierno en primera persona singular. Recién en la edición de 1638 (tomos I-II) los secretarios son cuatro. Los dos "editores" que figuran en el frontispicio de la obra recuerdan por su nombre la estructura original del libro. Cf. Buisseret y Barbiche, "Introduction”, Les aconomies royales de Sully, Op. cit. págs. xvii-xxiii
} 
no se presenta como el autor, sino como alguien que escucha a sus colaboradores mientras éstos le recuerdan sus hechos de gobierno. Siempre en la lógica de las precauciones, la edición del libro la encarga a un impresor de Auxerre, Jacques Bouquet, y hace que éste se instale con sus ayudantes en la Torre Béthune de su castillo, cerca de sus aposentos. ${ }^{24} \mathrm{~A}$ pesar de esto, el frontispicio de la obra no contiene referencia alguna al verdadero editor ni a la localidad donde se edita; en su lugar menciona la ciudad de "Amstelredam" y a dos impresores ostensiblemente ficticios: Alethinosgraphe de Cléantimélée y Graphexechon de Pistariste, en griego "Escritor verídico de gloria y virtud" y "Secretario emérito de alta probidad". ${ }^{25}$ Como ha explicado uno de los biógrafos de Sully, la impresión clandestina le permitió a Bouquet ser dispensado de la aprobación del rey. ${ }^{26}$

Un último aspecto de la difusión del proyecto paneuropeo tiene que ver con la manera como es dado a conocer. ${ }^{27}$ Además de las Memorias, el plan se difunde gracias a varios resúmenes o ediciones no exentos de problemas. La primera reseña, escrita por Agrippa d'Aubigné, uno de los cercanos consejeros de Enrique IV, aparece en el apéndice del tercer tomo de su Histoire Universelle de $1620 .{ }^{28} \mathrm{La}$ información que utiliza proviene de los manuscritos del Sully, aunque comenta sólo el primer proyecto e introduce ideas que le son ajenas, como una supuesta búsqueda de extensión territorial a expensas de Alemania y el deseo del rey de convertirse en emperador de Europa. El siguiente resumen es obra del preceptor de rey Luís XIV, Hardouin de Péréfixe, incluida en su Histoire du roi Henry le Grand de 1661. ${ }^{29}$ Péréfixe también abreva en los papeles de Sully, no siempre con exactitud, sobre todo en lo que toca al mecanismo de arbitraje, pero es una de las versiones que trascienden y llega a manos del abate de Saint Pierre, quien la reproduce en 1713 en el primer tomo de su libro dedicado a la confederación europea. ${ }^{30}$

La falta de unidad y el estilo agreste de las Memorias motivan una tercera vía de transmisión: la edición de 1745 de Pierre Mathurin, abate de Lécluse des

24 La edición se ampara en un contrato notarial y cuesta 5.223 libras. La Torre de Béthune, la última de las nueve torres del Castillo Sully-sur-Loire en ser construida, se encuentra en la parte posterior del edificio, en dirección opuesta a la entrada por la Torre Negra o Portal y comunicaba con las Torres Rosny y Villebon. Cf. Aristide, La fortune de Sully, Ob. cit. págs. 291-294.

25 Buisseret y Barbiche, "Introduction", Les aconomies royales de Sully, Op. cit. pág. xxiii, n. 1.

26 Carré, Sully, Ob. cit. págs. 378-379.

27 Para un análisis de la difusión general de la obra de Sully véase, entre otros: Pfister, "Les 'Economies royales' de Sully et le Grand Dessein de Henri IV", Ob. cit. Tomos 55-56; Puharré, L'Europe vue par Henri IV et Sully, Ob. cit. pág. 70 y ss; y Marie-Madeleine Martin, Sully le Grand, París: Éditions du Conquistador, 1959 , pág. 218 y ss.

28 Théodore Agrippa d'Aubigné, L'Histoire universelle du sieur d'Aubigné, qui, de la déroute d'Angers, desdits les affaires de France et les estrangères connues, jusques à la fin du siècle belliqueux, et puis, par un appendice séparé, descrit la desplorable mort d'Henri le Grand, Tomo III, Maillé: Jean Moussat, 1620, pág. 542 y ss.

29 Hardouin de Péréfixe de Beaumont, Histoire du roi Henry le Grand composée par Messire Harduvin de Péréfixe, Ámsterdam: Antoine Michiels, 1661, pág. 383 y ss.

30 Charles Irénée Castel, abate de Saint Pierre, Projet pour rendre la paix perpétuelle en Europe à Utrecht, Utrecht: Antoine Schouten, 1713 y 1717, París: Fayard, 1986, págs. 80-85, 666. 
Loges. ${ }^{31}$ A diferencia de las anteriores, no se trata de un resumen o comentario, sino de una versión que refunda la estructura y la forma del original con el fin de hacerlas más accesibles. No obstante su falta de acuerdo con el original, ${ }^{32}$ es la obra que consagra la popularidad de Sully a partir de la primera mitad del siglo XVIII, y probablemente es la que se importa y tiene relativo éxito en Estados Unidos a finales de ese siglo y principios del siguiente. ${ }^{33}$

\section{Controversia sobre su primacía histórica}

Antes que Sully diera a conocer su plan confederativo, varios autores habían formulado propósitos similares, Pierre Dubois, Dante Alighieri, Marsilius de Padua y Erasmo de Rótterdam, aunque en todos los casos se trataba de revivir la unidad cristiana del antiguo Impero romano. El plan de Sully se refiere a una Europa diferente, cuyos estados acaban de adquirir clara supremacía en el ordenamiento internacional. Pero, ¿es el primer antecedente de la integración internacional? A juzgar por otra de las controversias que genera la obra de Sully la respuesta no es categórica. Veamos más de cerca los términos del debate.

Mientras Sully preparaba la edición de las Memorias, en 1623 aparece en medio de la indiferencia general una obra pionera de los organismos multilaterales: Le nouveau Cynée: Ou discours des occasions et moyens d'establir une paix generale \& la liberté du commerce par tout le monde, escrita por Émeric Crucé, un oscuro sacerdote parisino. ${ }^{34}$ La escueta e injusta recepción que se tributa a la obra se compensa con el relativo entusiasmo de sus admiradores, quienes la consideran

31 Pierre Mathurin, abate de Lécluse des Loges (ed.), Mémoires de Maximilien de Béthune, duc de Sully, principal ministre de Henri le Grand, mis en ordre avec des remarques par M.L.D.L.D. l'abbé de Lécluse des Loges, Tomos I-III, Londres: s.n., 1745.

32 Según expresa Levesque de la Ravalière, el abate Lécluse des Loges "hace una historia a partir de las Memorias, rara vez [...] escribe las Memorias basándose en las Memorias". Citado en Buisseret, "The Legend of Sully", Ob. cit. pág. 184.

33 Cf. Puharré, L'Europe vue par Henri IV et Sully, Ob. cit. págs. 79-81. Los datos sobre la exportación de los libros de Sully a Estados Unidos se encuentran en: Howard Mumford Jones, "The Importation of French Books in Philadelphia, 1750-1800”, Modern Philology, Vol. 32, No. 2, noviembre, 1934, págs. 157-177. Sobre los cambios de imagen de Sully en la historia francesa, en buena medida resultado de las distintas versiones de su obra, véase: Lauren Avezou, Sully à travers l'histoire : Les avatars d'un mythe politique, Ginebra: Droz, , 2001. Avezou empieza su importante estudio sobre los "avatares" del personaje con una lectura integral de las Memorias, seguido del análisis del rechazo del rey Luís XIV, nieto de Enrique IV, la rehabilitación de su imagen como buen administrador iniciada por Boisguilbert, continuada en la primera mitad del siglo XIX por las tendencias nacionalistas francesas, hasta su papel más actual en la construcción de un imaginario histórico.

34 Émeric Crucé, Le nouveau Cynée: Ou discours des occasions et moyens d'establir une paix generale \& la liberté du commerce par tout le monde: Aux monarques \& souverains de ce temps, París: Villery, 1623. Para nuestro trabajo hemos empleado la edición facsímile de 1976. De la vida de Crucé se tienen escasos datos e incluso su nombre fue objeto de controversia hasta 1890, cuando Ernest Nys invalidó el empleo concomitante de Emericus Crucejus, Emery de la Croix o Lacroix. Cf. Nys, "Notices et notes diverses, Histoire littéraire du droit international", Revue de droit international et de législation comparée, Vol. XXII, 1890, págs. 365-382. 
como el primer proyecto de paz perpetua ${ }^{35}$ e incluso el "modelo básico" en el cual se habría inspirado Sully. ${ }^{36}$ Como sustento de esa hipótesis, aducen dos tipos de argumento; el primero, de orden cronológico, señala que la edición del Nuevo Cineas precede en dieciséis años a las Memorias; el segundo alude al paralelismo entre ambas obras y a sus puntos en común. ${ }^{37}$

El primer argumento parte de un hecho cierto, la tardía edición de los primeros tomos de las Memorias, pero simplifica en exceso su comprobación al descuidar otras fechas verificables. El manuscrito que contiene las ideas confederativas de Sully empieza a redactarse hacia 1611 y está listo en 1617. La existencia de esos papeles explica que el resumen de Agrippa d'Aubigné lleve tres años impreso cuando Crucé publica su obra. El segundo argumento, defendido por André Puharré, sostiene que la versión de 1638 de las Memorias retoma "bastantes ideas" del Nuevo Cineas, y cita como ejemplos la libertad religiosa y el consejo compuesto por los embajadores de los países confederados. ${ }^{38}$ Esta afirmación visiblemente se origina en una comparación textual y no en el estudio histórico capaz de separar los elementos originales de Crucé de aquellos que pertenecen a la tradición anfictiónica. En efecto, más que a la inventiva de Crucé, la estructura de la asamblea debe atribuirse a las anfictionías griegas, referente histórico al que apelan ambos autores, las cuales contemplaban la elección de los delegados mediante el voto popular o se limitaban a albergar a los representantes de los soberanos, es decir, a sus embajadores.

La tesis religiosa tampoco se sostiene. El principio de tolerancia de Sully, alimentado por sus propias convicciones y reflejado en los hechos de gobierno de Enrique IV, en particular el edicto de Nantes de 1598 y su política exterior en materia religiosa, se aplica esencialmente a las relaciones entre el catolicismo y el protestantismo. ${ }^{39}$ Aunque es una de las ramas del cristianismo, el culto ortodoxo es excluido de la confederación sulliana. En Crucé, en cambio, la libertad de culto concierne al conjunto de las religiones del mundo, incluyendo a los orientales y a los otomanos.

35 Thomas Willing Balch, "The Proposed International Tribunal of Arbitration of 1623”, Proceedings of the America Philosophical Society, Vol. 46, No. 186, abril-septiembre, 1907, pág. 306; Martin, Sully le Grand, París, Ob. cit. pág. 220.

36 Louis René Beres, "Examining the Logic of World Federal Government”, Publius, Vol. 4, No. 3, verano, 1974, pág. 78.

37 Pfister, "Les 'Economies royales' de Sully et le Grand Dessein de Henri IV”, Ob. cit. Tomo 54, pág. 330; Pierre Louis-Lucas, Un plan de paix générale et de liberté de commerce au XVII siècle. Le Nouveau Cynée d'Émeric Crucé (1623), París: Recueil Sirey, 1919, pág. 157.

38 Puharré, L'Europe vue par Henri IV et Sully, Ob. cit. págs. 86-89.

39 El edicto de Nantes cierra en Francia el periodo borrascoso de las guerras de religión, cuyo punto culminante es la Matanza de San Bartolomé. Ese decreto, firmado el 13 de abril de 1598 por Enrique IV, autoriza la libertad de culto de los protestantes y establece en su primer artículo la amnistía para todos los beligerantes. Sobre la política religiosa de Enrique IV, que busca el reconocimiento del principio de tolerancia en Holanda, Inglaterra y Alemania, véase: Anquez, Henri IV et l'Allemagne d'après les Memoires et la correspondance de Jacques Bongars, Ob.cit. págs. 177 y n. 
Dicho esto, es casi seguro que Sully llega a conocer la obra de Crucé y quizá retoma algunas de sus ideas en la edición de $1638 .{ }^{40}$ Sin embargo, son más relevantes las diferencias y peculiaridades de ambos autores. La visión europeísta del primero, que incluye un plan de reorganización territorial adverso a la dinastía de los Habsburgo, resulta hasta cierto punto contraria al enfoque multilateral, pacifista y respetuoso del status quo fronterizo del segundo. Es significativo que Sully y Crucé coincidan en la necesidad de que el rey de Francia promueva el proyecto de paz internacional. Para Sully se trata de una idea que seguramente comunicó a Enrique IV antes de 1610; $;^{41}$ en el caso de Crucé, empero, esa recomendación resulta absurda por cuanto supone que el monarca galo tendría interés en promover una confederación a cuya cabeza se encontrarían, antes que él, el Papa, el emperador otomano y el emperador germánico. Si bien el pasaje no dice mucho de Crucé, en cuyo sistema la intervención del rey es un dato periférico, en el caso de Sully es claramente necesario.

\section{Consideraciones finales}

Más allá de controversias, versiones adulteradas y rehabilitaciones, las Memorias, en particular el proyecto de República europea presentan el caso de una obra que trasciende las aspiraciones de un ministro de genio y funda una corriente de pensamiento jurídico político. Aunque la genealogía "sulliana" compulsa en varias tradiciones (la búsqueda de "paz perpetua" entre naciones, el ordenamiento jurídico de las relaciones internacionales, y la integración regional), su síntesis en la idea de una república confederada asienta un importante paradigma intelectual. Como tal, sirve de inspiración a los proyectos integracionistas del abate de Saint Pierre, Juan Jacobo Rousseau, Emmanuel Kant, el conde de Saint-Simon, Simón Bolívar y los congresos de unión hispanoamericana del siglo XIX.

Sin sorpresas, los debates que presiden la creación de la Unión Europea invocan el plan de Sully como el primer antecedente de un ideal que ha dominado el último medio siglo de la historia europea.

Recebido em 14 de maio de 2009 Aprovado em 20 de setembro de 2009

40 Lo contrario es poco factible debido a la amplia cultura de Sully. También consulta De recuperatione Terre Sancte de Dubois, editada por Jacques de Bongars en Gesta Dei per franco. Si bien los ingresos de Bongars son limitados, en parte por la política de austeridad de Sully, su biblioteca es una de las más prestigiosas de la época. Se compone de 3.000 volúmenes (incluyendo 1.300 eran incunables) y 500-600 manuscritos. Cf. Anquez, Henri IV et l'Allemagne d'après les Memoires et la correspondance de J. B. Ob. cit. págs. III-LXXVI.

41 La primera alusión manuscrita que hace Sully del Gran Designio, remonta a 1596. Cf. Pfister, "Les 'CEconomies royales' de Sully et le Grand Dessein de Henri IV”, Ob. cit. Tomo 55, pág. 67 y ss. 


\section{Abstract}

The present article analyses the writing, edition and diffusion of the Memories of the Duke of Sully. With that in mind, the first section refers to the context in which the work was made; the second presents general characteristics of the European confederation; and the third describes discrepancies of its versions. The fourth, fifth and sixth sections studies the chronology and the stages of the writing, the changes made in the manuscripts and their diffusion; the seventh examines the debate on the historical primacy of the Memories. The article tries to reconstruct the conditions that determine the elaboration and reception of the first Pan-European project.

\section{Resumen}

El presente artículo se consagra al análisis de la redacción, edición y difusión de las Memorias del duque de Sully. Con ese propósito, la prim-era sección refiere el contexto que rodea la preparación de la obra; la segunda presenta las características generales de la confederación y la tercera profundiza en las discrepancias de sus versiones; en la cuarta, quinta y la sexta se estudian la cronología y las etapas de la redacción, los cambios operados en los manuscritos y sus vías de difusión; la séptima examina el debate sobre la primacía histórica de las Memorias. El artículo pretende reconstruir las condiciones que determinan la elaboración y recepción del primer proyecto paneuropeo.

Palabras Ilave: Unión europea, Memorias del duque de Sully, confederación.

Keywords: European Union; Memories of the Duke of Sully, confederation. 